International Journal of Advanced Trends in Computer Science and Engineering

Available Online at http://www.warse.org/IJATCSE/static/pdf/file/ijatcse245942020.pdf

https://doi.org/10.30534/ijatcse/2020/245942020

\title{
eIC-Home Access: A Multi-Factor Home Security Framework Using Electronic Identity Card for Access Control
}

\author{
Julie Ann B. Susa ${ }^{1}$, Christina P. Atal ${ }^{2}$, Erwin Mariquina ${ }^{3}$, Alan V. Ranario ${ }^{4}$, Mary Ann M. Tejano \\ ${ }^{1}$ Technological Institute of the Philippines, Manila Philippines, jsusa.cpe@ tip.edu.ph \\ ${ }^{2}$ Universidad De Manila, Manila Philippines, atalchristina@gmail.com \\ ${ }^{3}$ International Electronics and Technical Institute, Alabang Philippines, emariquina@ yahoo.com \\ ${ }^{4}$ International Electronics and Technical Institute, Alabang Philippines, alanvranario@ gmail.com \\ ${ }^{5}$ Taguig City University, Taguig Philippines, marc49007@ gmail.com
}

\begin{abstract}
Security has become a major preoccupation in all homes around the world. Automated security devices nowadays are a valuable addition to a home where safety is a major concern. Vision-based surveillance systems have the advantage that they are easy to set up, low cost, and non-obtrusive. Here, a safety device was developed using sensors to detect any security breaches and send out Buzzer's high-intensity warning signal. The project is to create an advanced security system for the home. The first way to protect the system is to use the generated passcode of the owner. The proper combination he has made must be inserted before entering the owner. The second way to do this is to use a special RFID for each device. The obtained sensor is tapped onto the RFID. If the protection device is not completed after several attempts, an alarm is issued which is loud enough to alert nearby houses. The alarm can only be switched off via RFID or user passcode. Arduino Uno and sensors are utilized for this project. Therefore maximum security at home is preserved.
\end{abstract}

Key words: Arduino Uno, Buzzer, EEPROM, Home Security, Microcontroller, PIR Sensor, RFID.

\section{INTRODUCTION}

The safety of the home in everyday life is a very important factor. In the 21st century, it is an evolving problem. Safety is of primary importance to everyone and everywhere. Everyone wants to be protecting their house, business, banks, etc. This project describes a security device that can sense the security of an enterprise \& home. This is an advantageous and easy system of defense. Here our application uses Arduino as its controller to detect senses of motion and alerts to intimate others are given immediately by the buzzer. This paper is based on an embedded system where the home security microcontroller is used. This device is intended to implement a managed module based on a microcontroller that receives its instruction. This microcontroller will then execute the
Commands provided and then communicate the status of a given applicant.

Given the burglary incidents, securing a home is an indispensable task. The standard design of home security systems usually only controls the property and there are no physical control elements to the house itself. In today's sense, leaving the house unattended is that, as people are busy keeping up with their tight daily schedule. Most people have therefore selected the home protection system as the most secure way of securing their homes. All the body produces some heat energy that is invisible to human eyes in the form of an infrared. But, a laser sensor can detect that.

A home security system is an emerging technology that has recently been gaining much attention from homeowners. In newly built homes, the traditional hardwired system is simple to install; however, existing homes need a complex configuration of these systems that entail significant costs. Hence, an alternative to the hardwired was a wireless home protection network [1]. Home automation has become a far-reaching step from the last century and will increase in the years to come. Protection is an integral edge of sharp home applications or work. The new and growing clever homes thinking provides the inhabitants with a fun, attractive, and safe environment. Standard security schemes protect contract holders and their property from gate breakdowns by giving the signature warning [2]. The creation of security at home was a challenge for those who work in cities around the world. Home safety systems are designed to automate, improve security, communications, comfort, and save energy. A smart home system is designed to provide insinuated, accurate monitoring with various types of sensors. Owing to rising crime rates, home security has become a significant concern over these days. In the beginning, the protection system was relatively straightforward, offering simpler facilities. Yet nowadays the scheme contains many other facilities to make the city-homes more convenient, smarter, and more secure [3]. Safety has become a big concern in all homes around the world. Automated protective systems are a valuable addition to the home where safety and security is a major issue today. Vision-based security systems have the advantage of being 
easy, low cost and non-obtrusive to install. Here, a security technique has been implemented that uses sensors to detect any security breaches and send out the high-intensity alert signal via Buzzer. A protection strategy shall be controlled such as detecting intrusion, unauthorized entry into a building or protected area, and preventing such access from harming or damaging the safety of personnel and property. Security devices are mainly used for the protection of residential, commercial, industrial, and military properties against burglary (theft) or property damage as well as for the self-defense against intruders. Warning sirens secure vehicles and their contents, too. Also, the jails are using surveillance systems to track prisoners. Security is most prevalent among residential homeowners. Nowadays home protection and surveillance systems are an integral part of every new automated home. The development model of a safety system starts with evaluating people's needs, surveying existing equipment and hardware, evaluating product costs, making monitoring choices, and finally planning the installation [4]. There will be physical limitations to an attractive home automation market and a busy family and personal network. ARDUINO firewall and $\mathrm{Wi}-\mathrm{Fi}$, and this was the mini web server home automation. Arduino is an open-source electronics prototyping framework focused on lightweight, easy-to-use hardware, and software. For the microcontroller, the Arduino I board has 54 physical input/output pins [5]. The technology gives us the ability to improve the accessibility of various devices and therefore we can obtain an overall security solution. By using some of the sensors we could transform our houses into a Smart Home. These sensors should act as house eyes and ears [6]. Regular systems and services are not sufficient with the development of the cities and population size. A smart city system is required to accomplish this almost at present, and an expected service in the future [7].

The research is developing an innovative home protection system. The first way of security system is by using the owner's created passcode. Before entering the owner must insert the appropriate combination he made. The second way to do this is to use an RFID unique to each user. The RFID is tapped on the received sensor. If after several attempts the security system is not complied with, there will be an alarm that is loud enough to alarm nearby houses. The alarm can only be turned off by RFID or passcode from the user.

\section{REVIEW RELATED LITERATURE}

The related studies outlined in this section examine the concept of an advanced security system based on Arduino.

In today's modern society, where outbreaks of household and business fires, gas leakage, overcurrent accidents, theft, gas accumulation suffocation, etc. grow alarmingly, becoming a major source of danger and natural hazards, the need for protection cannot be overemphasized. Modern protection systems (if available) in developing countries perceive defense as solely intrusion-based, with high service and set-up costs, and hence the need for a smarter, more embedded security system. The GSM-based smart security system, using the introduced Arduino, use Passive Infrared (PIR), MQ2, MQ7, and DHT 11 sensors to detect intrusion, fuel gasses, carbon monoxide, and temperature threats respectively, and also integrates remote access and control capabilities. The concept of remote monitoring and control is implemented using the SIM900 GSM program interface, using both SMS calls and mobile phone calls. Both internal and external mode operating modes reduce the service's total operating demand, and therefore remote monitoring (RMS) is only used when the owner is currently away by using audio and visual alert forms. The unit houses the mighty Arduino Uno. The program resulted in cost savings, smart, lightweight, and more effective ways to implement safety alarms [8]. Protection and automation are a huge concern in our everyday lives. Today, the approach for developing residential and industrial automation and protection systems is being standardized. They agreed to increase these standards in this project through the combination of modern design methods and the design of affordable automated industrial and household protection systems. They're all keen to be as healthy as possible. The proposed basic hardware circuit allows each user to use this PIR, the Smoke alarm, wireless home security system. All the sensors and detectors are connected to the microcontroller via different types of interface circuits. The microcontroller will monitor all the sensors on an ongoing basis and the microcontroller will send the SMS through GSM modem to the mobile consumer if it detects any security problems. The complexity of the program's algorithm can be improved by adding a set of devices to make the energy house efficient. This study introduces a new concept and implementation of an effective security system based on GSM, and also provides the benefit of technological progress in everyday life [9]. Based on the work and the review by M. Andriansyah et al. of the home door security system facing any house in the capital, the proposed home protection solution is to develop a home door security system prototype using an e-KTP Radio Frequency Identification ( RFID) device that uses a microcontroller as a door map in an entryway-based digital smart home system. [10]. D. Chaudhuri has explained that In Security is one of today's major concerns. Security not only from increased crime but from daily life incidents as well. Proper measures should be taken in this present world of technological advancement to ensure the security and comfort of households, banks, and offices. Billions of rupees expended on services such as the fire brigade, the police, etc. can be put under control by using proper protection systems. The objective of this project is to combine smart home features with security system features to create a functional home control system. The study took into account all existing products and combined them to design a system that will not only automate the building but also take into account all the building's safety features. The system uses gas sensors that detect any potential gas leakage at the site. It's also equipped with smoke and temperature sensors to see if any fire breaks out in the house. It also features the role of intrusion detection by correctly positioning the passive infrared sensor (PIR 
sensor). All these sensors are well connected to a controlled microcontroller portion, which in case of any disaster will produce a proper output. A specific number of security services can be fed into the network so that in case of any emergency a notification previously created can be transmitted to that number. To improve the efficiency of the system from its predecessors, an in-depth review of previous systems was carried out [11]. Home security device project planning study depends on the program that uses a microcontroller and sensors such as Motion Sensors, Gas Sensor, and Door / Window Sensor Magnetic Switch. The new developments in the field of electronics have brought great improvements to human day-to-day life. My research presents the smart home automation device that uses a PIC microcontroller to do this. Implementing sensors such as motion, magnetic, and gas sensors that operate on and relay signals to the microcontroller is the process of creating a physical model that can be applied. The system operates the alarm system in case a house is a theft and a gas leak occurs inside the house. It also shows problems with the building. The proposed security system provides the overall hardware and software design framework and describes ways of implementing the house security system [12]. The Internet of Things (IoT) refers to the network of Internet-connected physical devices. It is rising at a very rapid pace currently, as a large number of devices are linked to the internal market. Using the Internet, this technology integrates ton-intelligent home appliances to work in unison. Home security is an extremely useful IoT application and offers essential benefits at an affordable price. This paper discusses the implementation of an Atmega 328P microcontroller to collect input from all the sensors and method them into a set of actions that manifest themselves in the form of the smart home security features. The ESP-01 microcontroller is used to connect this system to a WiFi network to keep the user informed, if any, about the suspicious activities. The house's motorized doors and windows can be operated from a digital smartphone through signaling. Forced entries within the residence typically appear the greatest threat to any house. The model can detect these intrusions into the house and transmit emergency services to the authorities' concerned 'helplines. The buzzer rings to warn the citizens inside the house and the room doors are shut down automatically to keep the inmates safe [13]. Arduino is an open opensource work that is comprised of both hardware and software. Hardware is a circuit board, i.e. programmable Microcontroller, and its applications are a built-in computer-operated growth environment tool used to write and upload the code to the Arduino board. It is widely used for electrical and electronics in most applications, as Arduino does not require a distinct piece of hardware. Developers upload physical board code whereas most of the preceding microcontrollers need a separate programmer to load physical board code. Besides that Arduino IDE uses a simplified version of $\mathrm{C}++$ that makes the program easy to understand. Arduino finally gives a basic form factor that shares microcontroller use in a more accessible package. The ATMega2560 is the basis for the
Arduino Mega 2560 Microcontroller Board.3 Materials and proposed system. [14]-[17] used the power of Arduino as microcontroller as their control system.

\section{METHODOLOGY}

\section{A. Components View}

Having a home automation system requires various hardware materials. Some of the essential components to get an idea about the proposed system are listed below.

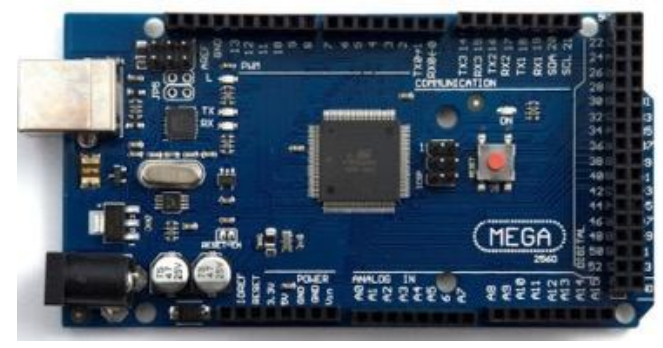

Figure 1: Arduino Mega 2560

The Arduino Mega 2560 as shown in Figure 1 is a microcontroller board based on ATmega2560 (Datasheet). It contains all the support needed for the microcontroller; simply link it to a computer with a USB cable, or power it to start with an AC to-DC adapter or battery. The Super is compatible with most shields from Arduino Duemilanove, or Diecimila.

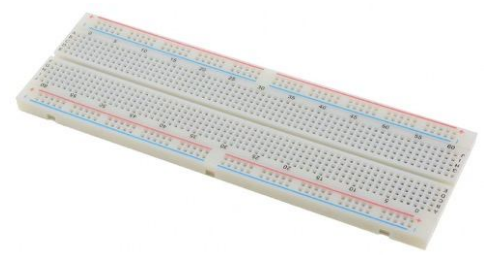

Figure 2: Bread Board

The breadboard as shown in Figure 2 is the foundation stone for electronic prototyping. Initially, it was just a piece of the bread plate, a piece of polished wood used to slice bread. The solderless breadboard (a.k.a. plugboard, a terminal array board) became available in the 1970s and today the word "breadboard" usually refers to these.

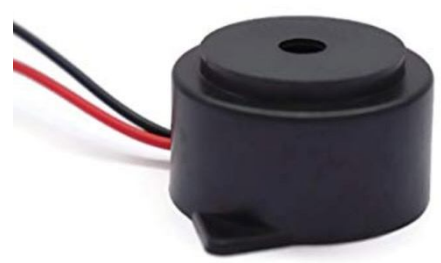

Figure 3: Buzzer

A buzzer or beeper as shown in Figure 3 is an audio signaling device that may be electrical, electromechanical or piezoelectric. Common types of buzzers and beepers include verification of alarm systems, clocks, and user inputs, which include mouse clicks or keystrokes. Efficient Buzzer 5V Rating power can be directly connected to a continuous tone, this segment of the specified sensor extension system and the 
combination board can provide a basic circuit design for plug-in and out.

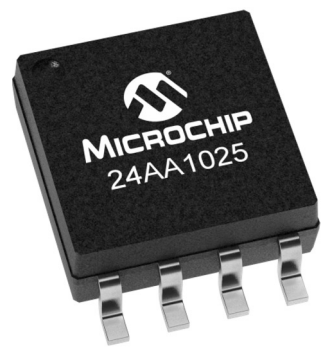

Figure 4: EEPROM

EEPROM (electrically erasable read-only memory) as shown in Figure 4 is a user-modifiable read-only memory (ROM) that can be repeatedly erased and reprogrammed by applying a higher than normal electrical voltage.

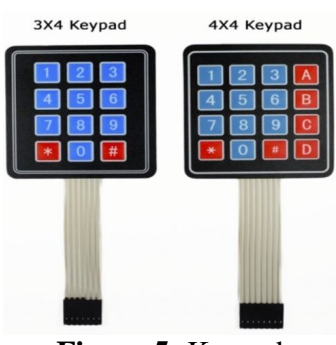

Figure 5: Keypad

Keypads as shown in Figure 5 are a perfect way to let the project communication with the users. You can use them for menu navigation, password entering, and games, and robot control.

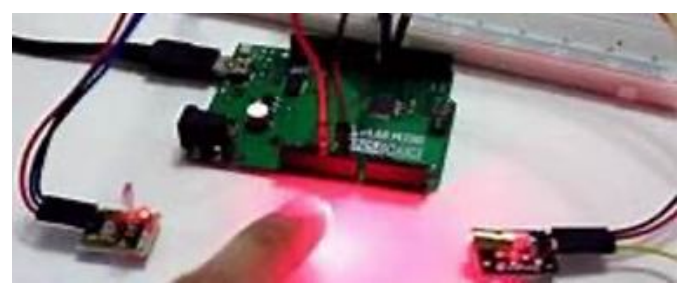

Figure 6: Laser Sensor

Laser sensors as shown in Figure 6 are used for the detection of small objects or mapping specific positions. These are known as traverse-beam sensors, retro-reflective sensors, or diffuse sensors for reflection. Laser light is made up of light waves of the same wave-length, with a set ratio of phase (coherence). Wavelength laser: $650 \mathrm{~nm}$ (red) with infinite range (vacuum).

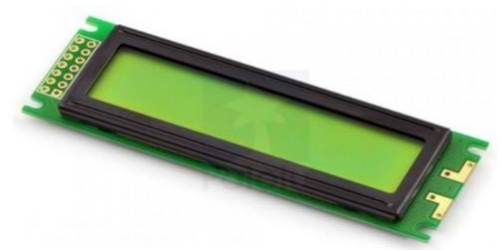

Figure 7: LCD Display
An LCD as shown I Figure 7 is an electronic screen module which uses liquid crystal to produce a visible image. A very basic module commonly used in DIY and Circuitry is the 16 auxiliary LCD screen. The 16-show turns 16 characters per row into 2 of those lines. Every character in this LCD is represented in a 5-pixel matrix.

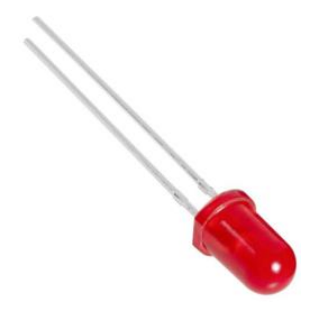

Figure 8: Led

A light-emitting diode (LED) as shown in Figures 8 and 9 is a semiconductor chip that emits visible light through an electric current. The light isn't especially bright, but appears at a particular wavelength in most LEDs and is monochromatic.

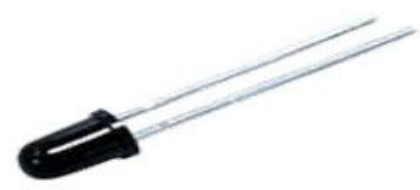

Figure 9: Photo Diode

A photodiode is a device with a semiconductor that converts light into electric current. In the photodiode, the current is generated when photons are absorbed. Photodiodes may include optical filters, integrated lenses, and may include large or small surface features. Photodiodes typically have a slower response time with increasing surface area. A large area photodiode is the common, conventional solar cell used for the generation of electric solar power.

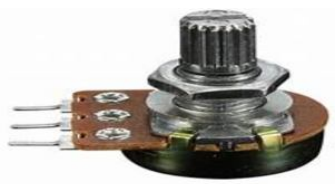

Figure 10: Potentiometer

The measurement device called a potentiometer as shown in Figure 10 is essentially a tension divider used to measure electrical potentiality (voltage); the part is an extension of the same concept, hence its name. Potentiometers are widely used for controlling electrical appliances, such as audio equipment volume controls. 


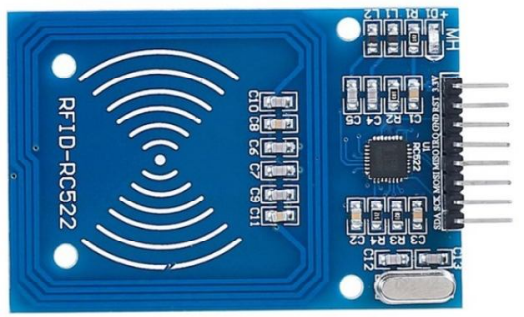

Figure 11: RFID Reader

Mifare RC522 as shown in Figure 11 is a completely integrated RFID card reader that continues to operate on contactless $13.56 \mathrm{MHz}$ interaction, built by NXP as low power consumption, low value, and compact size read and write chip, making it the easiest way to build smart meters and portable handhelds.

This module will fit into mass-production systems that are kept in hand immediately. The module uses a $3.3 \mathrm{~V}$ power source and, by connecting to it via the SPI protocol, can communicate directly with any CPU board to ensure higher language distance, stable operation.

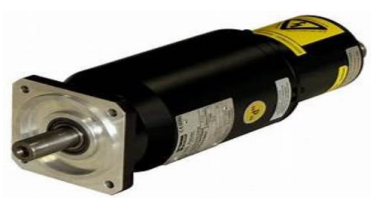

Figure 12: Servo Motor

A servomotor as shown in Figure 12 is a linear or rotary actuator that allows for accurate controls of angular or linear position, velocity, and acceleration. It is comprised of an appropriate motor, coupled with a location data sensor. It also contains a fairly sophisticated controller which is often a specialized module specifically designed for the use of servomotors.

\section{B. Schematic Diagram}

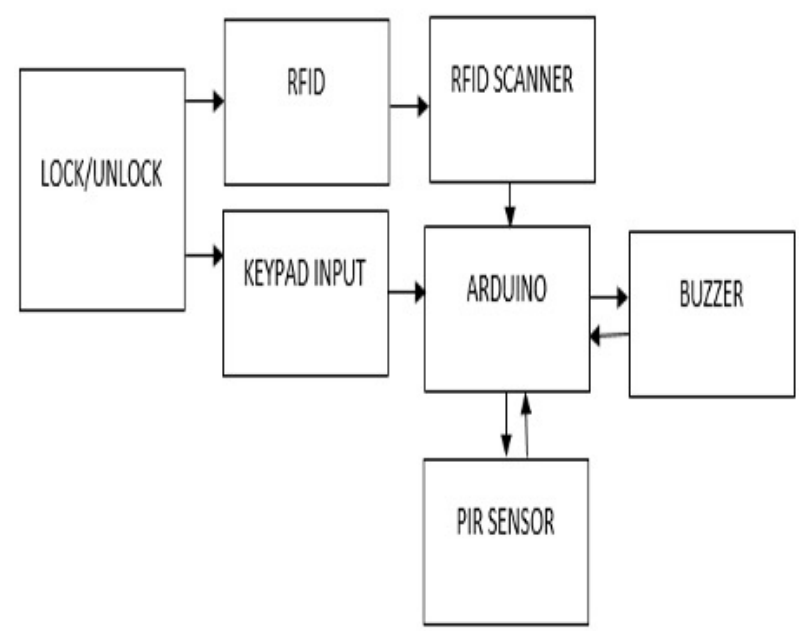

Figure 13: Schematic Diagram

Figure 13 illustrates the advanced home protection system utilizing Arduino Uno Architecture. It shows the components used, and how components can be linked together. The consumer will use the device in two ways. First is by using created passcode and second is by using the RFID. If the protection device is not complete after several attempts, an alarm will be issued which will be loud enough to alert nearby houses. The alarm can only be switched through RFID or a user passcode.

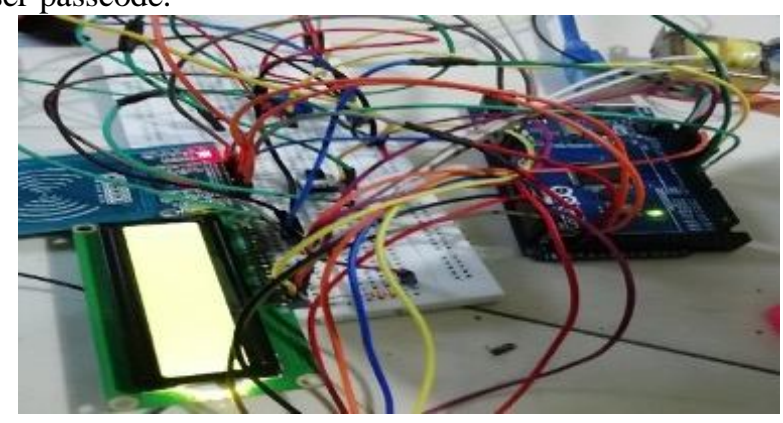

Figure 14: Different parts of Hardware Set up

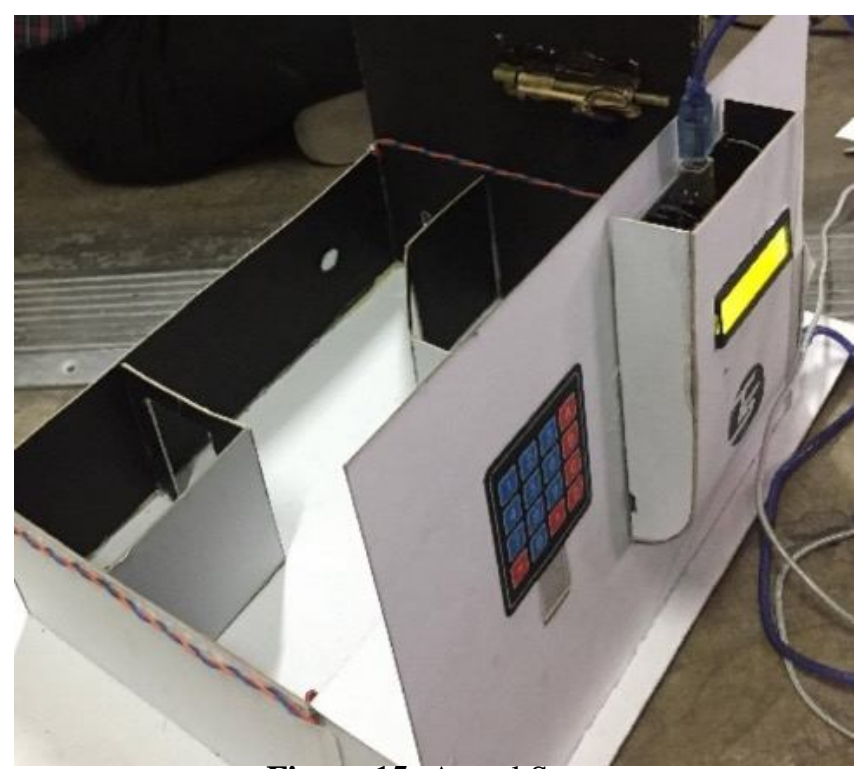

Figure 15: Actual Set up

\section{TESTING AND RESULT}

This section describes how the prototype of the proposed advanced home protection device is tested using Arduino Uno. Table 1 shown the successful login of a user using RFID and keypad. Table 2 shown the fastest way of locking and unlocking the device.

Table 1: RFID and Keypad Tests

\begin{tabular}{llll}
\hline Test Case & Expected Result & $\begin{array}{l}\text { Observed } \\
\text { Result }\end{array}$ & $\begin{array}{l}\text { Test } \\
\text { Result }\end{array}$ \\
\hline User should have successful login this system & SUCCESS & SUCCESS & PASS \\
User can log-in using RFID & SUCCESS & SUCCESS & PASS \\
User can log-in using keypad & SUCCESS & SUCCESS & PASS \\
User can log-in using both & SUCCESS & SUCCESS & PASS \\
\hline
\end{tabular}


Table 2: Time Response Tests

\begin{tabular}{ll}
\hline Number of Users & Time Response to Unlock (Seconds) \\
\hline 1 (Master's key) & $2 \mathrm{~s}$ \\
2 & $2 \mathrm{~s}$ \\
3 & $4 \mathrm{~s}$ \\
4 & $4 \mathrm{~s}$ \\
5 & $5 \mathrm{~s}$ \\
\hline
\end{tabular}

Figure 16 displays the blue line number of users and the gray line is the answer time for unlocking or locking the device. After typing the PIN the fastest way to trigger the lock is for 2 seconds. Nevertheless, if there are several users already saved or stored, the program can become slower, because it can take longer to read the entire database.

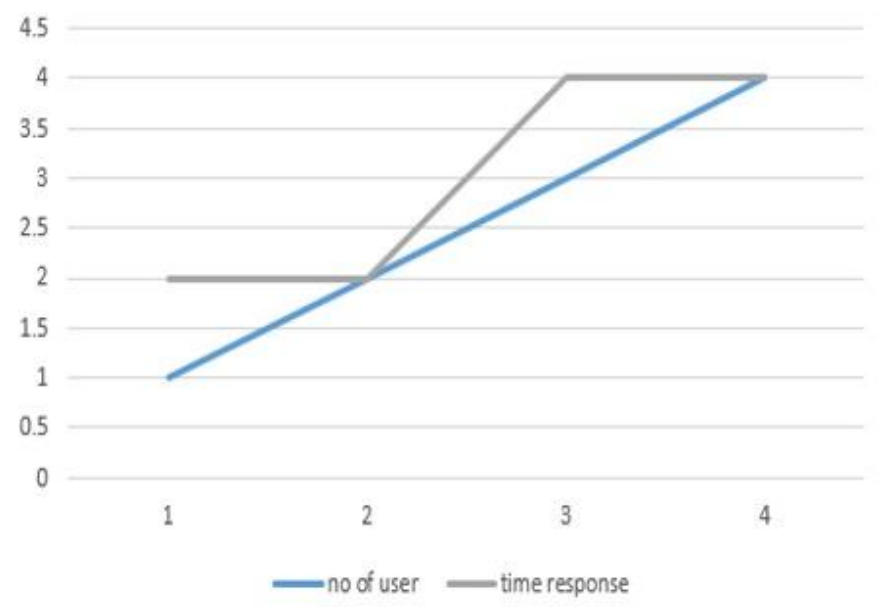

Figure 16: Time Response for Locking and Unlocking

\section{CONCLUSION}

The project describes the use of microcontrollers in the implementation of the Arduino-based home protection system that can help to detect and avoid various accidents by alerting the responsible person to use buzzers and sensors in the correct time.

\section{ACKNOWLEDGMENT}

The researcher wishes to express their appreciation of the following: Technological Institute of the Philippines, MR-SUAVE Laboratory, and the Technological Institute of the Philippines Microprocessors Lab.

\section{REFERENCES}

1. Designing a Wireless Home Network, Designing A Wireless Network, pp. 301-336, 2001. doi: 10.1016/b978-192899445-9/50014-5

2. M. Chandan, S. Sri Venkat Sumanth, G. Samhita and K. Priyanka Reddy, Design \& Development of a Home Security System Using IOT, International Journal of
Engineering \& Technology, vol. 7, no. 232, p. 374, 2018. doi: 10.14419/ijet.v7i2.32.15717

3. M. Hossain Jewel, M. Mostakim, M. Rahman et.al, Design and Development of a Versatile and Intelligent Home Security System, International Journal of Engineering and Manufacturing, vol. 4, pp. 60-72, 2017.

4. M. Hoque and C. Davidson, Design and implementation of an IoT-based smart home security system, International Journal of Networked and Distributed Computing, vol. 7, pp. 85-92, 2019.

5. J. A, R. Nagarajan, K. Satheeshkumar, N. Ajithkumar, P. Gopinath and S. Ranjithkumar, Intelligent Smart Home Automation and Security System Using Arduino and Wi-fi, International Journal Of Engineering And Computer Science, 2017. doi: 10.18535/ijecs/v6i3.53

6. N. Hashim, M. Abdul Razak and F. Idris, HOME SECURITY SYSTEM USING ZIGBEE, Jurnal Teknologi, vol. 74, no. 10, 2015. doi: 10.11113/jt.v74.4830

7. T.L Alumona, C.O Oranugo, C.E Eze, GSM Based Smart Security System Using Arduino, International Journal of Advanced Research in Computer and Communication Engineering, vol. 8, pp. 32-42, 2019.

8. R. K. Sharma, A. Mohammad, H. Kalita and D. Kalita, Android interface based GSM home security system, 2014 International Conference on Issues and Challenges in Intelligent Computing Techniques (ICICT), Ghaziabad, 2014, pp. 196-201, doi: 10.1109/ICICICT.2014.6781278.

9. M. Andriansyah, M. Subali, I. Purwanto et al., E-KTP as the basis of home security system using arduino UNO, Proceedings of the 2017 4th International Conference on Computer Applications and Information Processing Technology, CAIPT 2017, pp. 1-5, 2018.

10. U. Kaware, P. Jadhao, P. Neware et al., GSM based Home Security System with Autodialing, International Journal of Engineering Science and Computing, vol. 6, pp. 3788-3792, 2016.

11. V. D. Vaidya and P. Vishwakarma, A Comparative Analysis on Smart Home System to Control, Monitor and Secure Home, based on technologies like GSM, IOT, Bluetooth and PIC Microcontroller with ZigBee Modulation, 2018 International Conference on Smart City and Emerging Technology (ICSCET), Mumbai, 2018, pp. 1-4, doi: 10.1109/ICSCET.2018.8537381.

12. M. ShariqSuhail, G. ViswanathaReddy, G. Rambabu, C. V. R. DharmaSavarni and V. K. Mittal, Multi-functional secured smart home, 2016 International Conference on Advances in Computing, Communications and Informatics (ICACCI), Jaipur, 2016, pp. 2629-2634, doi: 10.1109/ICACCI.2016.7732455.

13. A. S. Alon and J. A. B. Susa, Wireless Hand Gesture Recognition for an Automatic Fan Speed Control System: Rule-Based Approach, 2020 16th IEEE International Colloquium on Signal Processing \& Its Applications (CSPA), Langkawi, Malaysia, 2020, pp. 250-254, doi: 10.1109/CSPA48992.2020.9068687.

14. J. B. Susa, Automatic Room Humidifier and Dehumidifier Controller using Arduino Uno, International Journal of Advanced Trends in 
Computer Science and Engineering, vol. 9, no. 2, pp. 2208-2212, 2020. doi: 10.30534/ijatcse/2020/198922020

15. M. F. Malbog, A Fuzzy Rule-Based Approach for Automatic Irrigation System through Controlled Soil Moisture Measurement, International Journal of Advanced Trends in Computer Science and Engineering, vol. 9, no. 2, pp. 2332-2337, 2020. doi: 10.30534/ijatcse/2020/216922020

16. J. Mindoro, Drowsy or Not?Early Drowsiness Detection utilizing Arduino Based on Electroencephalogram (EEG)

Neuro-Signal, International Journal of Advanced Trends in Computer Science and Engineering, vol. 9, no. 2, pp. 2221-2226, 2020. doi: 10.30534/ijatcse/2020/200922020

17. C. Casuat, RFID Controlled “GG" Pieces Ranking Detection with Watch-Dog Enable, International Journal of Advanced Trends in Computer Science and Engineering, vol. 9, no. 13, pp. 274-279, 2020. doi: 10.30534/ijatcse/2020/4191.32020 